\title{
Comparison of climate change scenarios for Sweden based on statistical and dynamical downscaling of monthly precipitation
}

\author{
Cecilia Hellström ${ }^{1}$, Deliang Chen ${ }^{1, *}$, Christine Achberger ${ }^{1}$, Jouni Räisänen ${ }^{2}$ \\ ${ }^{1}$ Earth Sciences Centre, Göteborg University, Box 460, 40530 Göteborg, Sweden \\ ${ }^{2}$ Rossby Centre, Swedish Meteorological and Hydrological Institute, 60176 Norrköping, Sweden
}

\begin{abstract}
Two dynamically and statistically downscaled precipitation scenarios for Sweden are compared with respect to changes in the mean. The dynamically downscaled scenarios are generated by a $44 \mathrm{~km}$ version of the Rossby Centre regional climate model (RCM). The RCM is driven by data from 2 global greenhouse gas simulations sharing a $2.6^{\circ} \mathrm{C}$ global warming, one made by the HadCM2 and the other by the ECHAM4 general circulation model (GCM). The statistical downscaling model driven by the same GCMs is regression-based and incorporates large-scale circulation indices of the 2 geostrophic wind components $(u$ and $v)$, total vorticity $(\xi)$ and large-scale humidity at $850 \mathrm{hPa}$ (q850) as predictors. The precipitation climates of the GCMs, RCMs and statistical models from the control runs are compared with respect to their ability to reproduce the observed seasonal cycle. Great improvements in the simulation of the seasonal cycle by all the downscaling models compared to the GCMs significantly increase the credibility of the downscaling models. The precipitation changes produced by the statistical models result from changes in all predictors, but the change in $\xi$ is the greatest contributor in southern Sweden followed by $q 850$ and $u$, while changes in $q 850$ have greater effects in the northern parts of the country. The temporal and spatial variability of precipitation changes are higher in the statistically downscaled scenarios than in the dynamically downscaled ones. Comparisons of the 4 scenarios show that the spread of the scenarios created by the statistical model is on average larger than that between the RCM scenarios. The relatively large average spread is mainly due to the large differences found in summer. The seasonally averaged difference of the dynamical and statistical scenarios for the ECHAM4-based downscaled scenarios is $12 \%$, and for the HadCM2 downscaled scenarios $21 \%$. The differences in annual precipitation change are smaller, on average $4.5 \%$ among the HadCM2-based downscaled scenarios, and $6.9 \%$ among the ECHAM4-based downscaling scenarios.
\end{abstract}

KEY WORDS: Statistical downscaling $\cdot$ Dynamical downscaling $\cdot$ Precipitation $\cdot$ Sweden Resale or republication not permitted without written consent of the publisher

\section{INTRODUCTION}

To enable impact assessments of climate change on, e.g., agriculture, forestry and energy production, regional and local climate change scenarios are needed. Such scenarios are not readily available from general circulation models (GCMs) with their current

*Corresponding author. E-mail: deliang@gvc.gu.se resolution. Therefore various techniques of downscaling GCM scenarios have been developed (Hewitson \& Crane 1996). Two commonly used methodologies are statistical downscaling and nesting of regional climate models (RCMs) within GCMs. Both methods have advantages and disadvantages. An important advantage of the RCMs is that they explicitly treat many of the physical processes controlling the regional climate. In statistical downscaling, these physical processes are assumed to be statistically incorporated indirectly 
through the links between the regional-scale climate and large-scale parameters. Compared to dynamical downscaling, statistical downscaling is computationally inexpensive and can easily be applied to any GCM output and adapted to local scale. Extended descriptions of statistical downscaling methods are given by Rummukainen (1997), Wilby \& Wigley (1997) and Zorita \& von Storch (1997).

Within the framework of SWECLIM (Swedish Regional Climate Modelling Programme) both dynamical and statistical downscaling have been carried out, using forcing from the 2 atmosphere-ocean GCMs ECHAM4/OPYC3 (Oberhuber 1993, Roeckner et al. 1996, 1999) and HadCM2 (Johns et al. 1997, Mitchell \& Johns 1997). The dynamical downscaling is performed using the $44 \mathrm{~km}$ version of the Rossby Centre RCM. The statistical model is a multiple regression model, which includes indices of large-scale atmospheric circulation and $850 \mathrm{hPa}$ specific humidity as predictors. The majority of statistical downscaling models have included only the large-scale atmospheric circulation and many of them show a high skill in simulating the observed climate. However, it has been recognized that the inclusion of humidity in statistical downscaling models of precipitation is of great importance for scenarios of a future climate with an enhanced greenhouse effect (Karl et al. 1990, Wilby \& Wigley 1997, Crane \& Hewitson 1998, Charles et al. 1999, Hewitson 1999, Murphy 1999, 2000). Murphy (2000) used stepwise regression to develop a statistical downscaling model of European precipitation and found that moisture was rarely selected as a predictor because of its weak effect on the natural precipitation variability. To avoid this problem on the basis of physical reasoning, moisture has been forced into the regression models disregarding its small contribution to the natural precipitation variability.

The main objective of this study is to systematically compare the mean changes in the 4 precipitation scenarios created by the statistical and the dynamical downscaling based on the 2 GCMs. A simple validation of the control climates produced by the models is also performed. Several validation methods exist. Ideally modeled time series should be compared with observed ones. This method has been used by, e.g., Murphy (1999), who calculated the correlation between simulated and observed precipitation and temperature series, and by Zorita \& von Storch (1999), who used a long validation time series to evaluate the ability of downscaling models to simulate the observed low-frequency oscillation. Such comparisons are possible only if the RCM is driven by observed data and if the time series of the predictors used in the statistical downscaling model are long enough to be split into a fitting and a validation series. None of these conditions are fulfilled in this work. The skill of the models is therefore described by their ability to simulate the seasonal precipitation cycle evident in precipitation data of a period that has not been used in the fitting of the statistical model. A reliable reproduction of the seasonal cycle is crucial in hydrological studies as well as in impact studies for agriculture and hydropower production.

Relatively few comparisons of results of dynamical and statistical downscaling methods have been performed (Kidson \& Thompson 1998, Murphy 1999, 2000, Mearns et al. 1999). Kidson \& Thompson (1998) evaluated the ability of the RAMS dynamical model and a regression-based model to estimate present local temperature and precipitation variations in New Zealand. Overall the 2 models showed similar skill. The results agree with those of Murphy (1999), who compared the skill of the UK Meteorological Office Unified Model (regional configuration) and a statistical downscaling model in simulating the present temperature and precipitation climate of Europe. Despite the comparable performance of the dynamical and statistical models in present-day climate estimations, the 2 models produced large differences in their climate change scenarios (Murphy 2000). Substantial differences are also found in regional climate change scenarios for eastern Nebraska derived by the RegCM2 and a semi-empirical statistical model (Mearns et al. 1999).

For regional impact studies it is important that the scenarios of the 2 methods converge, or that it is possible to determine which one of the two are the most reliable. Converging scenarios of the 2 methods cannot guarantee reliable results since both methods can be wrong. However, the difference between the scenarios does tell us something about the uncertainty.

\section{DATA AND MODELS USED}

\subsection{GCMs}

The GCMs used in this study are HadCM2 (Johns et al. 1997, Mitchell \& Johns 1997) and ECHAM4/OPYC3 (Oberhuber 1993, Roeckner et al. 1996, 1999). For both GCMs, two 10 yr time slices were used, one acting as a control period and the other as a scenario period representing a future climate with higher greenhouse gas concentrations. The actual forcing scenarios and time slice periods are somewhat different in the 2 cases. The HadCM2 boundary data are partial, unidentical reruns (for further discussion, see Räisänen et al. 2001) from 2 long simulations, a control run and a greenhouse run (GHG in Mitchell \& Johns 1997), in which gradually increasing $\mathrm{CO}_{2}$ represents the change in greenhouse gas forcing from the pre-industrial era. In the HadCM2 
model years, the period used extends from 2039 to 2049. The 2 ECHAM4 time slices are from the same transient greenhouse run (GHG in Roeckner et al. 1999), from the 1980s (control period) and the 2070s (scenario period). The increase in $\mathrm{CO}_{2}$ in HadCM2 between the control and scenario periods is about $150 \%$, and the increase in equivalent $\mathrm{CO}_{2}$ in ECHAM4 (which treats different greenhouse gases separately) slightly over $100 \%$. The difference between the 2 experiments in global mean radiative forcing is smaller, from Fig. 0.3 of Machenhauer et al. (1998) about $20 \%$. On one hand, radiative forcing is a logarithmic rather than a linear function of $\mathrm{CO}_{2}$, and, on the other hand, the amplitude of this proportionality is slightly model-dependent. In addition, somewhat fortuitously, the increase in global mean temperature between the control and scenario time slices is almost the same, $2.6^{\circ} \mathrm{C}$, in both HadCM2 and ECHAM4. In this sense, the HadCM2- and ECHAM4-based downscaled climate change scenarios are quantitatively comparable with each other, although the exact timing of these scenarios is a non-trivial issue.

\subsection{Regional climate model}

The dynamical downscaling experiments used in this comparison were made with the RCA1 version of the Rossby Centre Regional Atmospheric climate model for Northern and Central Europe. The model was run at $44 \mathrm{~km}$ horizontal resolution, in an area covering $114 \times 82$ grid boxes, and with 19 levels between the surface and $10 \mathrm{hPa}$. It was forced by the driving GCMs from its lateral boundaries (8-point relaxation zones were used) and from below, by sea-surface temperatures and deep soil temperatures.

RCA1 has been developed from the limited area weather forecast model HIRLAM (Källén 1996, Eerola et al. 1997) used in several European countries. Changes from HIRLAM include several updates to the soil and snow scheme and the inclusion of interactive modules for inland lakes (Ljungemyr et al. 1996, Omstedt 1999) and the Baltic Sea (Omstedt \& Nyberg 1996). These changes are described in some detail by Rummukainen et al. (2001). In addition, for the experiments discussed here, the original HIRLAM radiation scheme was also modified (Räisänen et al. 2000). Most importantly, the new radiation scheme allows for increasing $\mathrm{CO}_{2}$ in climate change simulations. To mimic the GCM forcing scenarios, $\mathrm{CO}_{2}$ was increased by $150 \%(100 \%)$ in the experiment with HadCM2 (ECHAM4) boundary data. At least partly as a result of this, the earlier tendency of RCA1 to simulate smaller warming in climate change experiments than the driving GCMs (see Räisänen et al. 2001) was essentially absent in the experiments studied here.

\subsection{Statistical downscaling model}

The model is a multiple regression model linking monthly precipitation at 42 Swedish stations and large-scale atmospheric circulation plus large-scale humidity at $850 \mathrm{hPa}$ over Northern Europe. The predictors are chosen by the following criteria: (1) they should be skillful in representing large-scale variability that is simulated by the GCMs; (2) they should be statistically significant contributors to the variability in precipitation, or they should represent important physical processes in the context of the enhanced greenhouse effect; (3) they should not be strongly correlated to each other. Four such predictors are finally chosen and used in the model. They are the 2 geostrophic wind components ( $u$ and $v$ ) as well as the total vorticity $(\xi)$ and large-scale specific humidity at $850 \mathrm{hPa}(q 850)$. The same predictors are used for all stations.

Large-scale circulation is represented by a set of circulation indices $(u, v$ and $\xi$ ) described by Chen (2000). The indices are computed from monthly meansea-level pressure (MSLP) data on a $5^{\circ}$ latitude by $10^{\circ}$ longitude grid-point basis bounded by latitudes 52.5 to $72.5^{\circ} \mathrm{N}$ and longitudes 5 to $27.5^{\circ} \mathrm{E}$. The large-scale specific humidity is an average over the area between 55 and $70^{\circ} \mathrm{N}$ and between 10 and $25^{\circ} \mathrm{E}$.

In the development of the statistical model, NCEP reanalysis (Kalnay and 21 others 1996) data (MSLP, the derived indices, and q850) for the period 1958 to 97 were used. The anomalies of the predictors and the station precipitation (predictand) were calculated with respect to their monthly 1961 to 1990 averages. A multiple linear regression model for the anomalies was developed for each month and station. A cross validation of the models shows that the models are skillful for all the seasons. Compared to the CCA downscaling models described in Busuioc et al. (2001a), these models show a considerable improvement.

For the scenario calculations, the GCM data for the control and scenarios runs were applied. Since the grid systems in the reanalysis and the GCMs are all different, all the reanalysis and GCM data are interpolated with a bi-linear method to the same grid as required by the calculation of the indices (for details, see Chen 2000).

\subsection{Precipitation data}

The precipitation data used for fitting the statistical models and for the verification of the control simulations are monthly time series measurements made at 42 Swedish stations (Table 1, Fig. 1) from 1921 to 1997. The data have been homogenized/corrected through 
Table 1. Stations used in the analyses. Lat = latitude, Lon = longitude, $\mathrm{H}=$ altitude, $\mathrm{Reg}=$ precipitation climate region

\begin{tabular}{|c|c|c|c|c|c|c|c|c|c|}
\hline Station & Lat $\left({ }^{\circ} \mathrm{N}\right)$ & Lon $\left({ }^{\circ} \mathrm{E}\right)$ & $\mathrm{H}(\mathrm{m})$ & Reg & Station & Lat $\left({ }^{\circ} \mathrm{N}\right)$ & Lon $\left({ }^{\circ} \mathrm{E}\right)$ & $\mathrm{H}(\mathrm{m})$ & Reg \\
\hline 1. Falsterbo & 55.23 & 12.49 & 5 & 1 & 22. Malung & 60.41 & 13.43 & 308 & 2 \\
\hline 2. Halmstad & 56.40 & 12.53 & 10 & 2 & 23. Grängesberg & 60.05 & 14.59 & 315 & 2 \\
\hline 3. Havraryd & 56.48 & 13.08 & 185 & 2 & 24. Falun & 60.37 & 15.40 & 160 & 2 \\
\hline 4. Växjö & 56.52 & 14.48 & 166 & 2 & 25. Sveg & 62.01 & 14.12 & 432 & 3 \\
\hline 5. Hoburg & 56.55 & 18.09 & 38 & 1 & 26. Sösjö & 62.46 & 15.30 & 430 & 3 \\
\hline 6. Vinga & 57.38 & 11.37 & 19 & 2 & 27. Sidsjö & 62.23 & 17.17 & 60 & 3 \\
\hline 7. Säve & 57.47 & 11.53 & 20 & 2 & 28. Härnösand & 62.38 & 17.57 & 8 & 3 \\
\hline 8. Borås & 57.46 & 12.57 & 135 & 2 & 29. Östersund & 63.11 & 14.30 & 376 & 3 \\
\hline 9. Krokshult & 57.23 & 16.05 & 130 & 1 & 30. Junsele & 63.42 & 16.51 & 210 & 3 \\
\hline 10. Ölands norra udde & 57.22 & 17.06 & 4 & 1 & 31. Holmögadd & 63.36 & 20.46 & 6 & 3 \\
\hline 11. Visby & 57.40 & 18.21 & 42 & 1 & 32. Leipikvattnet & 64.56 & 14.10 & 475 & 3 \\
\hline 12. Håvelund & 58.57 & 11.26 & 100 & 2 & 33. Lövånger & 64.22 & 21.20 & 21 & 3 \\
\hline 13. Vänersborg & 58.21 & 12.22 & 50 & 2 & 34. Hemavan & 65.49 & 15.06 & 475 & 3 \\
\hline 14. Ålberga & 58.45 & 16.33 & 25 & 2 & 35. Stensele & 65.04 & 17.09 & 325 & 3 \\
\hline 15. Landsort & 58.45 & 17.52 & 13 & 2 & 36. Piteå & 65.19 & 21.28 & 6 & 3 \\
\hline 16. Gotska Sandön & 58.24 & 19.12 & 12 & 1 & 37. Haparanda & 65.50 & 24.09 & 6 & 4 \\
\hline 17. Karlstad & 59.22 & 13.28 & 46 & 2 & 38. Kvikkjokk & 66.53 & 18.01 & 320 & 4 \\
\hline 18. Lisjö & 59.42 & 16.04 & 60 & 2 & 39. Tjåmotis & 66.55 & 18.32 & 300 & 4 \\
\hline 19. Uppsala & 59.52 & 17.38 & 13 & 2 & 40. Jokkmokk & 66.37 & 19.50 & 255 & 4 \\
\hline 20. Stockholm & 59.21 & 18.04 & 44 & 2 & 41. Abisko & 68.21 & 18.49 & 388 & 4 \\
\hline 21. Svenska Högarna & 59.27 & 19.30 & 12 & 2 & 42. Karesuando & 68.27 & 22.27 & 330 & 4 \\
\hline
\end{tabular}

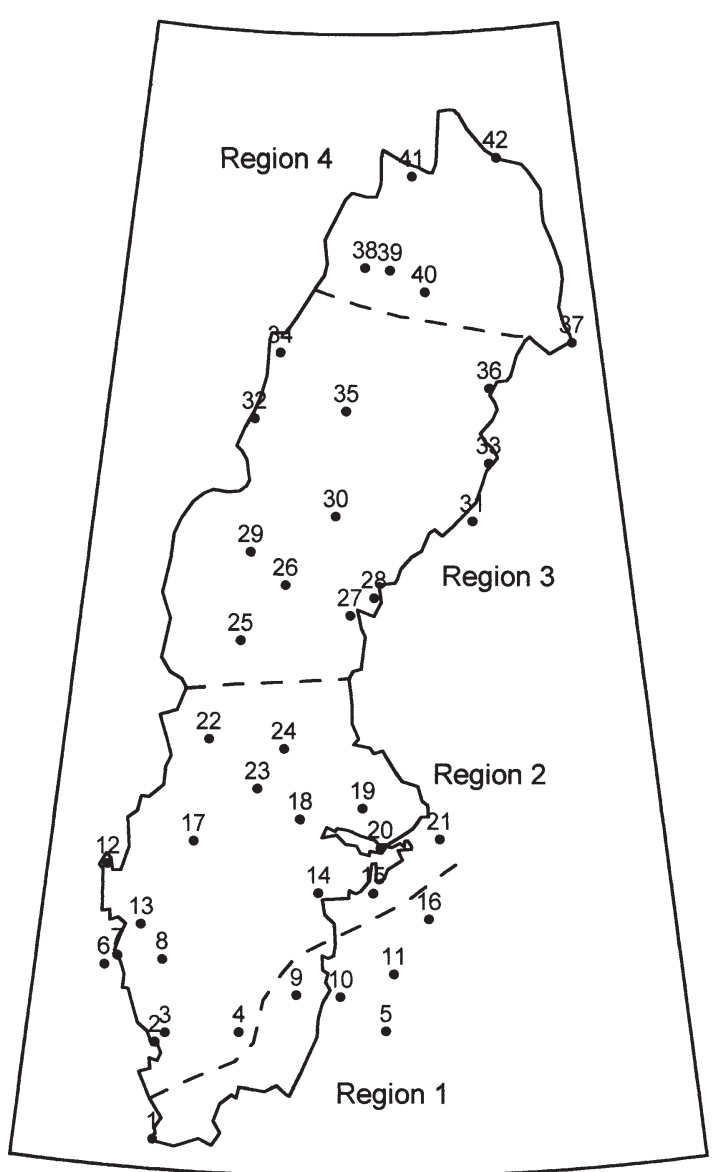

Fig. 1. Stations used. Broken lines indicate the boundaries between the 4 regions with similar precipitation variability the NACD program (Frich et al. 1996). They have recently been updated and provided by the Swedish Meteorological and Hydrological Institute (SMHI). Details about most of the stations can also be found in Busuioc et al. (2001b).

\section{RESULTS}

For the sake of briefness the RCM experiments driven by the HadCM2 and ECHAM4 are referred to as DDH and DDE, respectively. The statistical models applied to HadCM2 and ECHAM4 are referred to as $\mathrm{SDH}$ and SDE, respectively.

\subsection{Seasonal cycle}

Prior to the comparison of the scenarios, an examination of the performance of the downscaling methods under the control runs is made. The downscaling models and the GCMs are compared with the observed precipitation climate (1921-1950) with respect to their ability to reproduce the seasonal cycle. Note that the statistical models were developed for each month separately. Therefore, the seasonal cycle should be well represented by the statistical model. However, since data during 1921-1950 were not used in fitting the statistical model, it is still interesting to see how close the reconstructed seasonal cycle lies to the observed ones. The analysis is made for 4 stations, 
each representing a region of similar precipitation variability (Fig. 1). The 4 regions were distinguished in an earlier work (Busuioc et al. 2001b) using EOF and cluster analysis of annual precipitation. The 4 regions represent (1) the south-easternmost part of Sweden, (2) the southern part of the country excluding region 1), (3) the middle and the southern part of northern Sweden $\left(\sim 61\right.$ to $\left.66^{\circ} \mathrm{N}\right)$, and (4) northernmost Sweden $\left(\sim 66\right.$ to $\left.69^{\circ} \mathrm{N}\right)$. Table 1 lists the position of each station within its region. In the comparison the GCM and RCM data are bi-linearly interpolated to the coordinates of the 4 selected stations (Krokshult, Vänersborg, Junsele \& Kvikkjokk).

The seasonal cycles of the 4 stations for observed, statistically downscaled, and dynamically modeled results are displayed in Fig. 2. The correlation coefficients of observed and downscaled data are listed in Table 2.

The observed precipitation has a maximum in summer (JJA) followed by autumn (SON) for all of the 4 stations. The smallest amounts of precipitation fall in February, March and April. This type of seasonal cycle is not reproduced by the 2 GCMs, which have cycles negatively or not correlated to the observed ones. Both the dynamically and statistically based downscaling models give much better simulations of the seasonal cycle, although the improvement varies with model and station. With respect to the correlation coefficient, the statistical model applied to ECHAM4 data shows the best results (mean $r=0.81$ ). It gives, however, precipitation amounts that are too high in late summer and autumn for Krokshult, autumn for Vänersborg, and in July for Junsele \& Kvikkjokk. The RCM driven by ECHAM4 results also reproduces the seasonal cycle well except for Vänersborg, but it has rather large positive biases year round. Such a positive bias can to a lesser extent be found in the HadCM2-driven RCM results as well, except in summer. SDH tends to produce a precipitation maximum in autumn for southern Sweden and a strong negative bias in June for the northern stations.
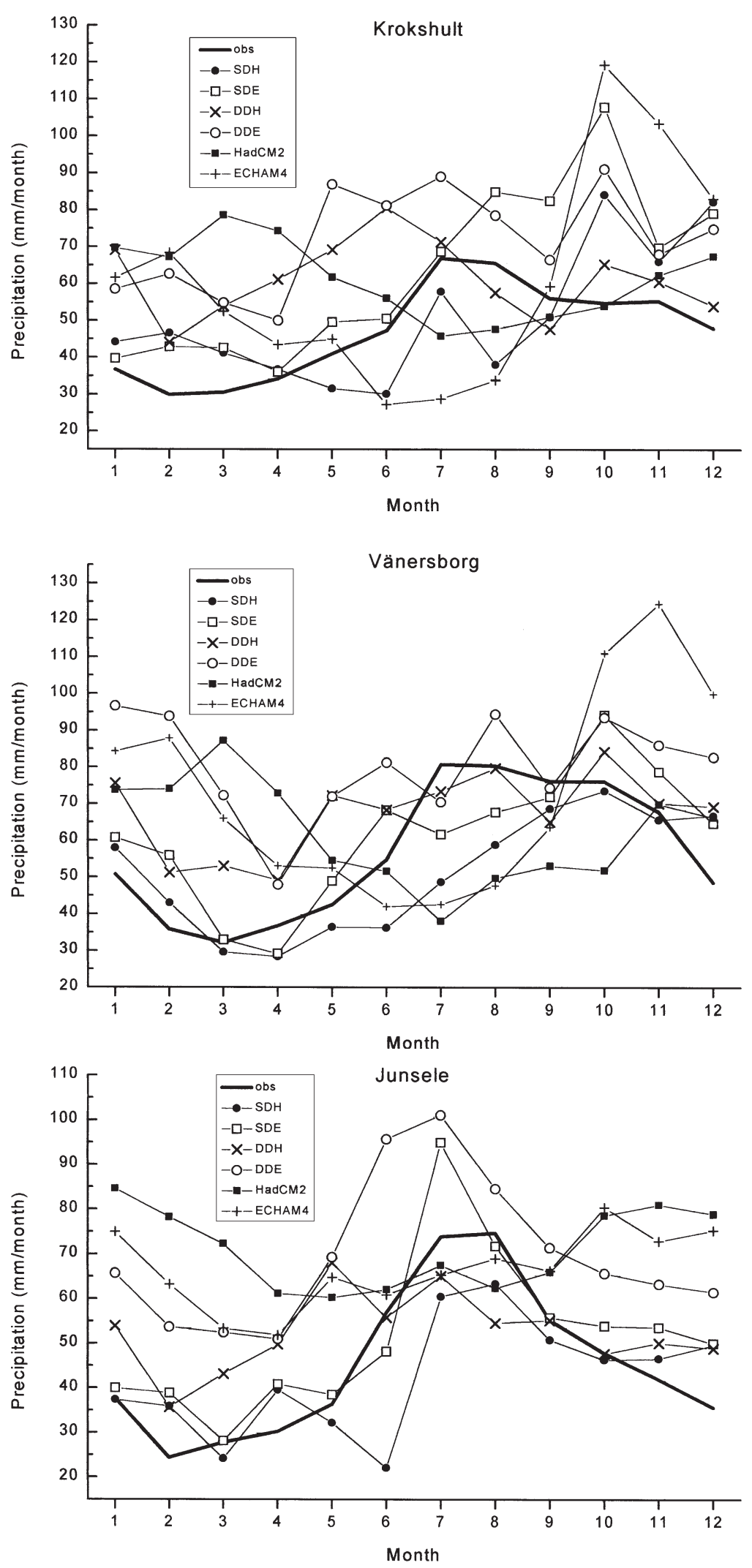

Fig. 2 (above and following page). Seasonal cycle of observed and modeled (control run) precipitation 


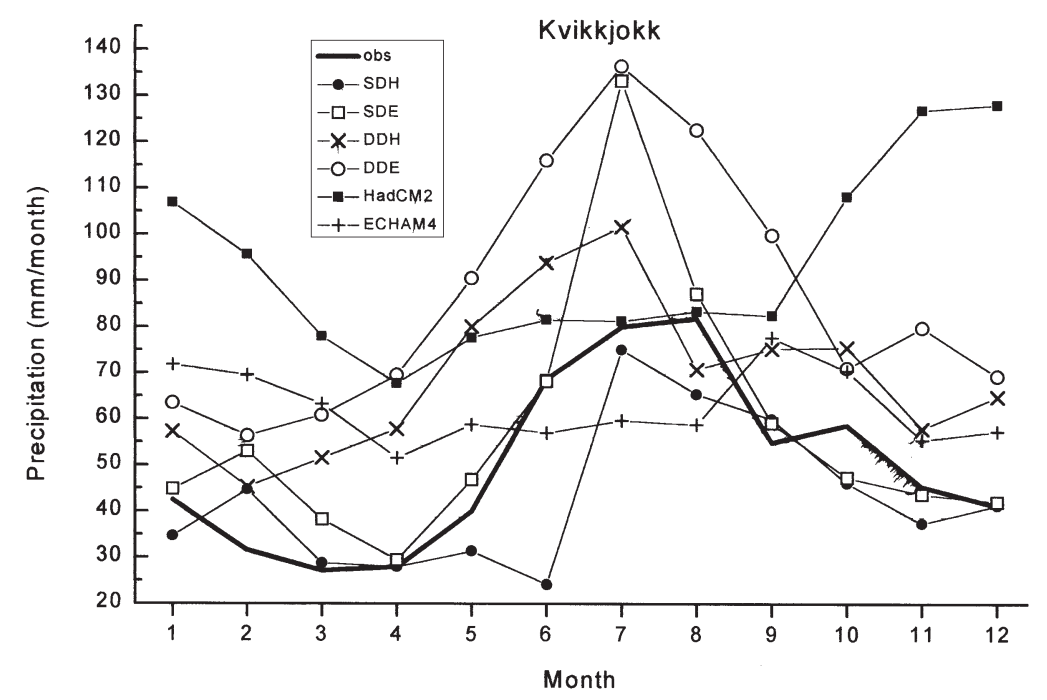

Fig. 2 (continued)

\subsection{Climate change scenarios}

The results of the scenarios of seasonal (DJF = winter, $\mathrm{MAM}=$ spring, $\mathrm{JJA}=$ summer and SON = autumn) mean precipitation, expressed as a percentage change, of the dynamical and statistical downscaling models are given in Fig. 3. To make a more quantitative comparison of the scenarios, the seasonal and annual mean changes are calculated for the 4 regions described in Section 3.1. The mean changes are calculated as averages of all stations included in each region (Table 1) and are plotted in Fig. 4.

\subsubsection{Winter}

Generally DDH produces significantly higher positive changes than the rest of the models over the whole country except in the south-east (Region 1). However, in the northern part of the country the spatial structure is similar in all models, with N-S- to NE-SW-oriented isolines. The 2 statistical models and DDE show negative changes in all parts of the country except in the northernmost part and in the relatively high altitude area in the westernmost part of northern Sweden. The statistical models tend to give larger negative values. Note that the relatively strong gradients produced by the statistical models are caused by small-scale effects of certain stations and can lead to marked differences in the patterns. The differences between DDH and SDH are fairly large in winter $(\sim 20 \%)$.

The changes produced by the statistical models are explained by changes in the large-scale predictors of the 2 GCMs. The seasonal mean values of the changes in the predictors are listed in Table 3. In winter $u$ is positively correlated with station precipitation in northern and southwestern Sweden (not shown). The highest correlation is found in the westernmost part of northern Sweden. Southerly winds also result in positive precipitation anomalies, except in the westernmost part of northern Sweden. The most important predictor is vorticity, with the exception of northwestern Sweden. Positive correlations between station precipitation and $q 850$ are found over the whole country except in Region 1. The large-scale $q 850$ is positively connected to the westerly and south-westerly advection of maritime North Atlantic air. In Region 1, however, the precipitation is found to be positively correlated to easterly and south-easterly advection. Hence, a general increase in $q 850$ for all kinds of large-scale circulation types, as can be expected as a result of an enhanced greenhouse effect, cannot be captured in the statistical model for Region 1. Therefore the scenario of the statistical models for Region 1 is considered to be unreliable in winter. For Regions 2 and 3 the increased $u$ and $q 850$ enhance the precipitation amount, but this is not enough to create positive changes because of the large decreases in $\xi$ and $v$. However, in the northernmost part of Sweden, where the mean effects of $v$ and $\xi$ are smaller, the negative changes in these variables are not large enough to counteract the effects of the increased $u$ and $q 850$.

\subsubsection{Spring}

With respect to the orientation of the isolines, the spatial structure of the changes obtained from the statistical model is similar in southern and northernmost Sweden. The size of the changes differs in southern

Table 2. Correlation coefficients between observed and modeled seasonal cycles. ${ }^{*}$ Statistically significant at $5 \%$

\begin{tabular}{|lccccc|}
\hline & Krokshult & Vänersborg & Junsele & Kvikkjokk & Mean \\
\hline SDH & 0.35 & $0.70^{*}$ & $0.64^{*}$ & $0.68^{*}$ & $0.59^{*}$ \\
SDE & $0.77^{*}$ & $0.75^{*}$ & $0.88^{*}$ & $0.83^{*}$ & $0.81^{*}$ \\
DDH & 0.21 & $0.73^{*}$ & 0.57 & $0.77^{*}$ & 0.57 \\
DDE & $0.67^{*}$ & 0.30 & $0.89^{*}$ & $0.89^{*}$ & $0.69^{*}$ \\
HadCM2 & $-0.90^{*}$ & $-0.77^{*}$ & -0.38 & -0.09 & -0.54 \\
MPI & 0.00 & 0.02 & 0.23 & -0.01 & -0.06 \\
& & & & & \\
\hline
\end{tabular}



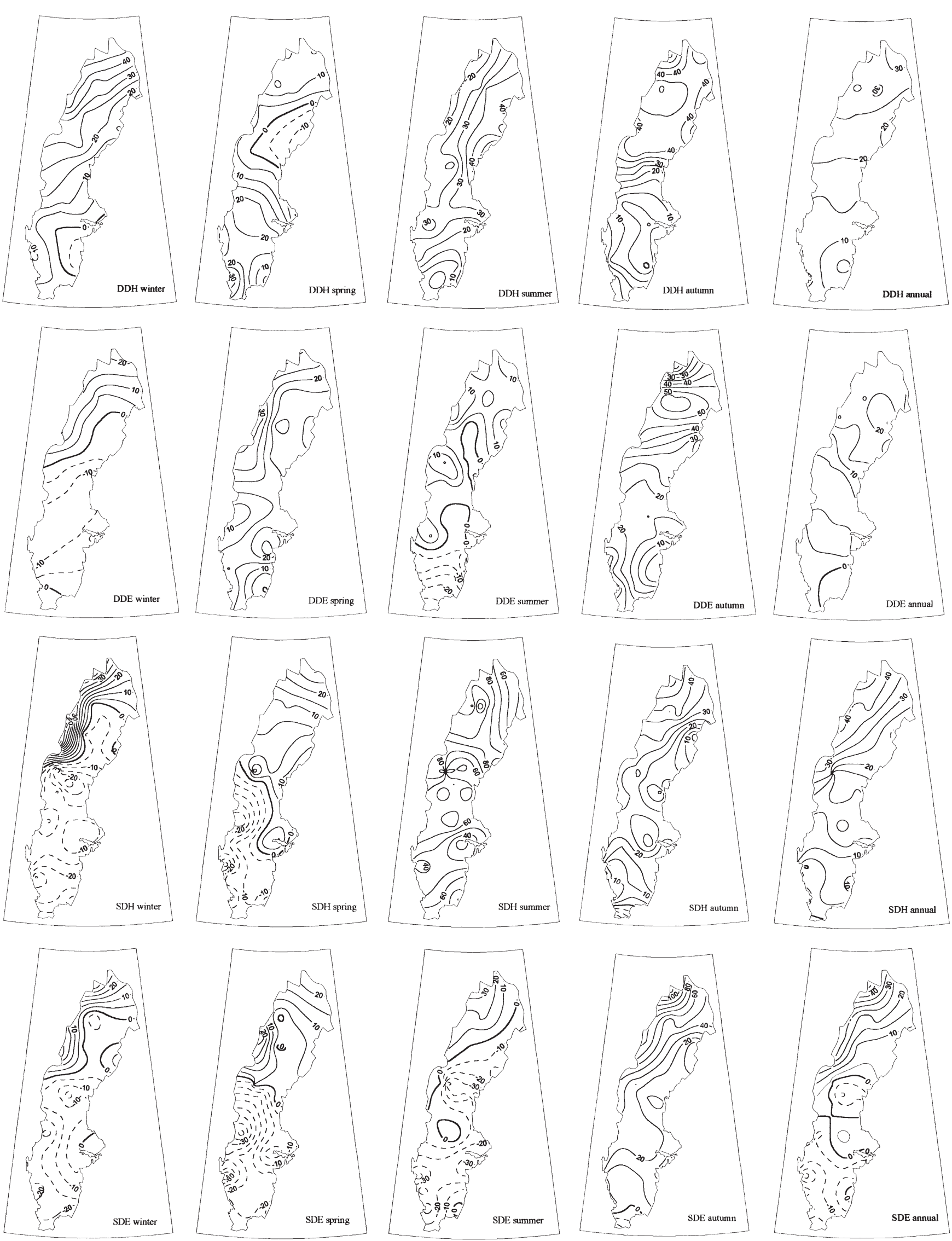

Fig. 3. Changes in precipitation [100\% $\times($ scenario - control)/control] for the dynamical and statistical downscaling models 

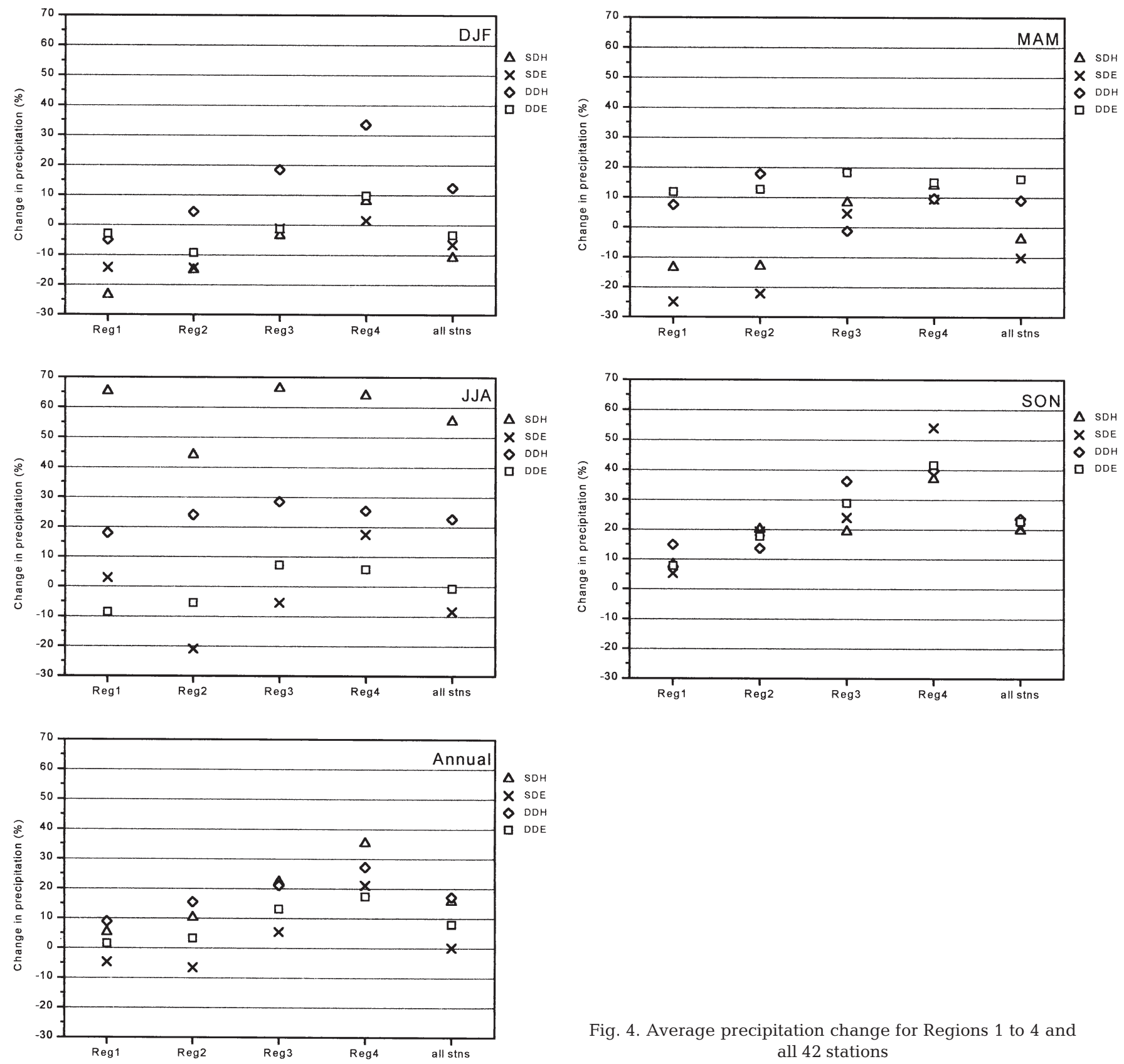

Fig. 4. Average precipitation change for Regions 1 to 4 and all 42 stations

Sweden. Similarities can also be found in the northern part in the DDE and SDE patterns. In southern Sweden (Regions 1 and 2) the dynamically and statistically downscaled results differ significantly $(\sim 20 \%)$. The statistical models produce negative changes, whereas the dynamical produce positive ones. The differences between the 2 statistical model results are also relatively large $(\sim 10 \%)$.

A difference of $\sim 20 \%$ is found between the 2 dynamically downscaled changes for Region 3, whereas the difference of the statistically downscaled changes is smaller. All models except DDH give positive changes

for the region. The results of Region 4 converge for all models.

The links between station precipitation and the predictors in spring are generally similar to those found in winter, but the magnitudes are somewhat lower for $u$, $V$ and $q 850$ for the whole country and for $\xi$ in northern Sweden. No correlation between $q 850$ and precipitation is evident in Region 1. All changes in the predictors, besides that in $q 850$, favor a reduction of precipitation in Region 1. The reduced precipitation amount in Region 2 in SDE seems to be caused mainly by negative changes in $V$ and in SDH by negative 
Table 3. Means of GCM predictors. $\mathrm{cl}=$ control climate, $\mathrm{sc}=$ scenario, Had $=$ HadCM2, ECH $=\mathrm{ECHAM} 4, u=u$-wind, $v=v$-wind, $\xi=$ total vorticity, $q 850=$ specific humidity at $850 \mathrm{hPa}, \Delta=$ change $(\mathrm{sc}-\mathrm{cl})$. All the circulation indices have the units of hPa per $10^{\circ}$ latitude at $60^{\circ} \mathrm{N}$. $q 850$ has the unit $\mathrm{g} \mathrm{kg}^{-1}$

\begin{tabular}{|c|c|c|c|c|c|c|c|c|c|c|}
\hline & \multicolumn{2}{|c|}{ DJF } & \multicolumn{2}{|c|}{ MAM } & \multicolumn{2}{|c|}{ JJA } & \multicolumn{2}{|c|}{ SON } & \multicolumn{2}{|c|}{ Year } \\
\hline & Had & $\mathrm{ECH}$ & Had & $\mathrm{ECH}$ & Had & $\mathrm{ECH}$ & Had & $\mathrm{ECH}$ & Had & $\mathrm{ECH}$ \\
\hline$u(\mathrm{cl})$ & 2.1 & 5.3 & -1.3 & 0.4 & 1.9 & 2.4 & 3.4 & 1.5 & 1.5 & 2.4 \\
\hline$u(\mathrm{sc})$ & 4.7 & 5.9 & -0.4 & 3.4 & 3.5 & 2.9 & 6.2 & 6.3 & 3.5 & 4.6 \\
\hline$\Delta u$ & 2.6 & 0.6 & 0.9 & 3.0 & 1.6 & 0.5 & 2.8 & 4.8 & 2.0 & 2.2 \\
\hline$V(\mathrm{cl})$ & 3.6 & 3.4 & 1.5 & 1.0 & -0.6 & -0.4 & 1.6 & 2.2 & 1.5 & 1.5 \\
\hline$V(\mathrm{sc})$ & 2.2 & -0.6 & 1.4 & -0.8 & -0.2 & -1.4 & 1.7 & 2.3 & 1.2 & -0.1 \\
\hline$\Delta v$ & -1.4 & -2.8 & -0.1 & -1.8 & 0.4 & -1.0 & 0.1 & 0.1 & -0.3 & -1.6 \\
\hline$\xi(\mathrm{cl})$ & 2.5 & 3.0 & -3.9 & 1.3 & -3.1 & 3.6 & -1.0 & 3.4 & -1.4 & 2.8 \\
\hline$\xi(\mathrm{sc})$ & -5.0 & 1.4 & -4.6 & 1.0 & 1.9 & -1.1 & 1.1 & 4.7 & -1.7 & 1.5 \\
\hline$\Delta \xi$ & -7.5 & -1.6 & -0.7 & -0.3 & 5 & -3.7 & 2.1 & 1.3 & -0.3 & -1.3 \\
\hline$q 850(\mathrm{cl})$ & 2.1 & 2.1 & 2.6 & 3.0 & 4.8 & 5.6 & 3.4 & 3.5 & 3.2 & 3.6 \\
\hline$q 850(\mathrm{sc})$ & 2.8 & 2.6 & 3.3 & 3.6 & 5.7 & 6.9 & 4.3 & 4.9 & 4.0 & 4.5 \\
\hline$\Delta q 850$ & 0.7 & 0.5 & 0.7 & 0.6 & 0.9 & 1.3 & 0.9 & 1.4 & 0.8 & 0.9 \\
\hline
\end{tabular}

changes in $\xi$. This is also true for Region 1. In Region 3, where $u$ is negatively linked with precipitation for some stations and positively for others, the positive changes in precipitation in the statistical models are most likely due to increased $q 850$. The increased spring precipitation in Region 4 is also an effect of the positive $q 850$ changes, but higher $u$ in the scenarios is also of importance in this area.

\subsubsection{Summer}

The spatial patterns and magnitudes of the changes show little similarity among the 4 models. The differences among the regional averages are very large and the range between $\mathrm{SDH}$ and SDE is as much as $72 \%$ for Region 3. Generally, the smallest differences are found between SDE and DDE ( 12\%). The relationships between the predictors and station precipitation resemble those of the spring months. The changes in the predictors given by HadCM2 and ECHAM4 have wide ranges, especially for $\xi$. This certainly causes the large spread between the changes in SDH and SDE. Due to the high correlation between precipitation and $\xi$, the increase in $\xi$ in HadCM2 is the main reason for the extremely high increases in SDH summer precipitation.

The large differences between the SDH and SDE results may partly be associated with the high interannual variability found in the SDH control climate in summer. For the 4 stations representing the 4 predefined precipitation regions the interannual variability is about $50 \%$ higher in $\mathrm{SDH}$ than in $\mathrm{DDH}$ in summer and more than $100 \%$ higher than in HadCM2. Such high interannual variability is not found in the observed (1921-1950) data, however. Hence, the summer scenarios of $\mathrm{SDH}$ are considered less reliable and should be taken with caution.

\subsubsection{Autumn}

DDH and DDE show similar patterns of change with respect to both spatial structure and magnitude. Similar spatial structures are also evident in the SDE and SDH patterns, although the magnitude of the change is different. For example, in the northwest the precipitation change reaches $>100 \%$ in SDE, whereas in $\mathrm{SDH}$ the highest value is $\sim 50 \%$. The differences in the regional averages between the changes in the models are relatively small. The largest spreads are found for DDH-SDH, Region 3 (16.9\%), and SDE-SDH, Region 4 $(17.3 \%)$. Both HadCM2 and ECHAM4 simulate large increases in $u$ (especially ECHAM4) and $\xi$ (especially HadCM2). Precipitation is strongly linked with $u$ only in northwestern Sweden, and this can explain the relatively high increase in autumn precipitation in SDE in northwestern Sweden and Region 4. For Regions 2 and 3 the differences between the changes given by $\mathrm{SDH}$ and SDE are relatively small. This suggests that for Regions 2 and 3, where $q 850$ is positively correlated with precipitation, the higher increase in HadCM2 $\xi$ is largely compensated by the larger positive change in q850 in ECHAM4.

\subsubsection{Annual}

The annual changes in precipitation are positive for all models in all regions except for SDE in Regions 1 and 2 . The positive changes in precipitation in SDE and SDH are the result of higher $u$ and $q 850$. The neg- 
ative changes for SDE in Regions 1 and 2 could be explained by negative changes in $\xi$ in ECHAM4.

Similar precipitation changes do not guarantee that the scenarios are correct. However, converging results of the statistical and dynamical downscaling methods can add more confidence in the results. In view of this, small differences between DDH and SDH and between DDE and SDE are positive. The differences in the changes of annual precipitation between DDH and SDH and between DDE and SDE are smaller than those of DDH-DDE and SDE-SDH. The mean difference between DDH and SDH for all regions is $4.5 \%$ and that between DDE and SDE is $6.9 \%$. Those values can be compared with that of DDH and DDE, which is $9.4 \%$, and that of SDE and SDH, which is $14.4 \%$. The difference in the precipitation changes in the models does not follow this pattern on a seasonal basis, however. The size of the differences between the models varies a lot with season and region. Averaging of the differences for all seasons and regions gives a value of $21 \%$ between DDH and SDH, $12 \%$ between DDE and SDE, $13 \%$ between DDH and DDE, and $20 \%$ between $\mathrm{SDH}$ and SDE. The great difference between SDH and SDE in summer is the main contribution to the relatively large all-season difference. For the other seasons the difference between SDH and SDE is about equal to the mean difference between DDH and DDE.

To examine the spatial variability of changes in average precipitation, the standard deviation of the average precipitation changes of the 42 stations is calculated for each season and model (Table 4). This kind of analysis might reflect the representation of local feedback effects in the models. Generally the statistical models give higher spatial variability than the dynamical models driven by the corresponding GCMs. The only exception is SDH-DDH in autumn. It should be noted that, when comparing the spatial variability of changes produced by statistical and dynamical models, the comparison is made between point and spatially averaged $(44 \mathrm{~km} \times 44 \mathrm{~km})$ data.

\section{CONCLUSIONS}

The main aim of this work is to compare statistically and dynamically downscaled precipitation scenarios for Sweden. It is found that the statistical downscaling model and the RCM are more skillful than the driving GCMs in reproducing the seasonal precipitation cycle. Both statistical and dynamical downscaling models show nearly equal skill in reproducing the seasonal precipitation cycle, although the statistical model applied to ECHAM4 data followed by the ECHAM4driven RCM performed somewhat better than the others.
Table 4. Spatial variability of precipitation changes

\begin{tabular}{|lrrrrr|}
\hline & DJF & MAM & JJA & SON & Year \\
\hline SDH & 20.8 & 14.9 & 21.3 & 12.9 & 17.5 \\
DDH & 14.6 & 10.8 & 10.6 & 15.4 & 12.9 \\
SDE & 14.2 & 17.8 & 22.2 & 23.2 & 19.4 \\
DDE & 9.2 & 7.4 & 11.2 & 16.4 & 11.1 \\
\hline
\end{tabular}

The changes found in the statistically downscaled scenarios can be traced to changes in the GCM predictors. In winter and spring a large reduction in $\xi$ creates negative changes in the precipitation amount. The decreases are smaller in the northern part of Sweden, where increased $u$ and $q 850$ have a greater effect than in the south. For summer the $2 \mathrm{GCMs}$ produce large changes of different sign in $\xi$ and $v$, leading to strongly diverging results in SDH and SDE. Increases in $u$ produced by the ECHAM4 give large positive precipitation changes in the northwestern part of the country in autumn. For southern and middle Sweden higher $\xi$ in HadCM2 and higher $q 850$ in ECHAM4 seem to be the major contributors to the precipitation increases.

The differences between the scenarios produced by the statistical downscaling model are generally larger than those of the RCM. The statistical downscalings are also associated with higher temporal and spatial variations of change. Part of this can be explained by the fact that the statistical model predicts precipitation at a station, whereas the RCM computes precipitation for a $44 \times 44 \mathrm{~km}^{2}$ area. Also, part of the relatively large differences in the statistical model scenarios can be explained by very high interannual variability found in the summer precipitation control climate of the statistical downscaling model applied to the HadCM2 data. In summer the interannual variability is $\sim 50 \%$ higher in $\mathrm{SDH}$ than in DDH.

The models that give the most similar scenarios vary with season. In winter it is SDE-SDH, followed by DDESDE that is associated with the smallest divergences, and in spring it is SDE-SDH, followed by DDE-DDH. In summer a wide spread between all models except DDE-SDE is evident. The differences are generally smallest in autumn, followed by winter and spring. On average the difference between the scenarios of the 4 regions is about the same, while the differences among the 4 seasons are significant. In winter the divergences in the model scenarios are smallest in the south and increase northward, whereas the opposite is true in spring. The reliability is low for all regions in summer, and in autumn only small differences are obtained for all regions. The average difference in change for all seasons and regions was $12 \%$ for DDE-SDE and $21 \%$ for DDH-SDH. The differences in the annual precipitation changes were lower, $4.5 \%$ for $\mathrm{DDH}$ and $\mathrm{SDH}$, and $6.9 \%$ for DDE and SDE. 
Acknowledgements. This work has been possible through the SWECLIM Programme supported by MISTRA and SMHI. The authors thank Hans Alexandersson for providing the precipitation data. This research is also partly supported by 2 NFR grants (G-AA/GU 11739-300 and G11739-302). The HadCM2 data were provided by the Hadley Centre, and the ECHAM4 data by the Max Planck Institute for Meteorology and the German Climate Computing Centre.

\section{LITERATURE CITED}

Busuioc A, Chen D, Hellström C (2001a) Performance of statistical downscaling models in GCM validation and regional climate change estimates: application for Swedish precipitation. Int J Climatol 21:557-578

Busuioc A, Chen D, Hellström C (2001b) Temporal and spatial variability of precipitation in Sweden and its link with the large-scale atmospheric circulation. Tellus 53A(3): 348-367

Charles SP, Bates BC, Whetton PH, Hughes JP (1999) Validation of downscaling models for changed climate conditions: case study of southwestern Australia. Clim Res 12: $1-14$

Chen D (2000) A monthly circulation climatology for Sweden and its application to a winter temperature case study. Int J Climatol 20:1067-1076

Crane RG, Hewitson BC (1998) Doubled $\mathrm{CO}_{2}$ precipitation changes for the Susquehanna Basin: down-scaling from the GENESIS General Circulation Model. Int J Climatol 18:65-76

Eerola K, Salmond D, Gustafsson N, Garcia-Moya JA, Lönnberg P, Järvenoja S (1997) A parallel version of the HIRLAM forecast model: strategy and results. In: Hoffmann GR, Kreitz N (eds) Making its mark: proceedings of the seventh ECMWF workshop on the use of parallel processors in meteorology. Reading, UK, November 1996, p 134-143

Frich F, Alexandersson H, Ashcroft J, Dahlström B and 15 others (1996) North Atlantic Climatological Dataset (NACD Version 1): Final Report. DNMI Report

Hewitson BC (1999) Deriving regional precipitation scenarios from general circulation models. Report K751/1/99, Water Research Commission, Pretoria

Hewitson BC, Crane RG (1996) Climate downscaling: techniques and application. Clim Res 7:85-95

Johns TC, Carnell RE, Crossley JF, Gregory JM, Mitchell JFB, Senior CA, Tett SFB, Wood RA (1997) The second Hadley Centre coupled ocean-atmosphere GCM: model description, spinup and validation. Clim Dyn 13:103-134

Källén E (ed) (1996) HIRLAM documentation manual. System 2.5. SMHI, Norrköping, Sweden

Kalnay E, Kanamitsu M, Kistler R, Collins W and 18 others (1996) The NCEP/NCAR 40-year reanalysis project. Bull Am Meteorol Soc 77:437-471

Karl TR, Wang WC, Schlesinger ME, Knight RW, Portman D (1990) A method of relating General Circulation Model simulated climate to the observed local climate. Part I: Seasonal statistics. J Clim 3:1053-1079

Kidson JW, Thompson CS (1998) A comparison of statistical and model-based downscaling techniques for estimating local climate variations. J Clim 11:735-753

Ljungemyr P, Gustafsson N, Omstedt A (1996) Parameteriza-

Editorial responsibility: Hans von Storch,

Geesthacht, Germany tion of lake thermodynamics in a high resolution weather forecasting model. Tellus 48A:608-621

Machenhauer B, Windelband $M$, Botzet M, Christensen $\mathrm{JH}_{\text {, }}$ Déqué M, Jones RG, Ruti PM, Visconti G (1998) Validation and analysis of regional present-day climate and climate change simulations over Europe. Max-Planck-Institut für Meteorologie, Report No. 275, Hamburg

Mearns LO, Bogardi I, Giorgi F, Matyasovszky I, Palecki M, (1999) Comparison of climate change scenarios generated from regional climate model experiments and statistical downscaling. J Geophys Res 104:6603-6621

Mitchell JFB, Johns TC (1997) On modification of global warming by sulphate aerosols. J Clim 10:245-267

Murphy J (1999) An evaluation of statistical and dynamical techniques for downscaling local climate. J Clim 12: $2256-2284$

Murphy J (2000) Predictions of climate change over Europe using statistical and dynamical techniques. Int J Climatol 20:489-501

Oberhuber JM (1993) Simulation of the Atlantic circulation with a coupled sea ice-mixed layer-isopycnal general circulation model. Part I: Model description. J Phys Oceanogr 22:808-829

Omstedt A (1999) Forecasting ice on lakes, estuaries and shelf seas. In: Wettlaufer JS, Dash JG, Untersteiner N (eds) Ice physics in the natural and endangered environment, NATO ASI Vol I 56, Springer-Verlag, Berlin, p 185-208

Omstedt A, Nyberg L (1996) Response of Baltic Sea ice to seasonal, interannual forcing and climate change. Tellus 48A 644-662

Räisänen P, Rummukainen M, Räisänen J (2000) Modification of the HIRLAM radiation scheme for use in the Rossby Centre regional atmospheric climate model. Report No. 49, Department of Meteorology, University of Helsinki

Räisänen J, Rummukainen M, Ullerstig A (2001) Downscaling of greenhouse gas induced climate change in two GCMs with the Rossby Centre regional climate model for northern Europe. Tellus 53A:168-191

Roeckner E, Arpe K, Bengtsson L, Christoph M and 6 others (1996) The atmospheric general circulation model ECHAM-4: model description and simulation of presentday climate. Max-Planck-Institut für Meteorologie, Report No. 218, Hamburg

Roeckner E, Bengtsson L, Feichter J, Lelieveld J, Rodhe H (1999) Transient climate change simulations with a coupled atmosphere-ocean GCM including the tropospheric sulfur cycle. J Clim 12:3004-3032

Rummukainen M (1997) Methods for statistical downscaling of GCM simulations. RMK No. 80, Swedish Meteorological and Hydrological Institute, Norrköping

Rummukainen M, Räisänen J, Bringfelt B, Ullerstig A, Omstedt A, Willén U, Hansson U (2001) A regional climate model for northern Europe-model description and results from the downscaling of two GCM control simulations. Clim Dyn 17:339-359

Wilby RL, Wigley TML (1997) Downscaling general circulation model output: a review of methods and limitations. Prog Phys Geogr 21:530-548

Zorita E, von Storch H (1997) A survey of statistical downscaling techniques. GKSS Rep 97/E/20, Geesthacht

Zorita E, von Storch H (1999) The analog method as a simple statistical downscaling technique: comparison with more complicated methods. J Clim 12:2474-2489

Submitted: October 10, 2000; Accepted: June 24, 2001

Proofs received from author(s): November 7, 2001 